\title{
Pre- and Post-irradiation Effects upon Lethality and Reversion in Salmonella typhimurium
}

\author{
*By P. H. WILliAMS AND C. H. CLARKE \\ School of Biological Sciences, University of East Anglia, Norwich, NOR $88 C$
}

(Accepted for publication I5 July I97I)

SUMMARY

Lag, exponential and stationary phase cells of Salmonella typhimurium LT-2 $\left(\operatorname{trp} C_{3}\right)$ grown in nutrient broth or tryptophan-supplemented minimal medium were irradiated with doses of u.v. up to $570 \mathrm{ergs} / \mathrm{mm}^{2}$. Casein hydrolysate supplementation of the post-irradiation plating medjum causes enhanced survival only for lag and exponential phase broth-grown and exponential phase minimalgrown cells. Caffeine invariably leads to decreased survival levels and abolition of any casein hydrolysate enhancement of survival. Cells of all six growth conditions give induced $\mathrm{Trp}^{+}$reversions, often due to suppressor mutations, on plating media containing casein hydrolysate. Only for minimal-grown lag and exponential phase cells do any induced $\mathrm{Trp}^{+}$appear on media devoid of casein hydrolysate supplementation. In these cases too, caffeine has a definite antimutagenic action. Mutation frequency decline (MFD) experiments revealed that those cells exhibiting a casein hydrolysate enhancement of survival on plates also show a delayed onset of MFD and a fall of survival, after an initial delay, in liquid minimal medium. MFD experiments in liquid do not give a complete quantitative explanation for the $\operatorname{Trp}^{+}$revertant yields found on plates. We suggest that intracellular free amino acid pool sizes may be a common factor in the correlations which we have observed.

\section{INTRODUCTION}

It has long been known that supplementation of the immediate post-irradiation plating medium with nutrient broth (Demerec \& Cahn, 1953) or a mixture of amino acids (Witkin, 1956), greatly enhances the yield of ultraviolet-induced reversions to prototrophy in several bacterial strains. This broth effect was studied in considerable detail by Witkin (1956) who showed that the amino acid mixture, to have its enhancing effect on revertant yield, needed to be present only for a short initial part of the incubation period after the u.v. irradiation. This broth effect on reversions, observed on plates of solid medium, has subsequently been interpreted in terms of mutation frequency decline (MFD). MFD is the rapid and irreversible fall in u.v.-induced revertant numbers which is observed if irradiated bacteria are incubated immediately after irradiation in liquid minimal medium devoid of amino acids (Doudney \& Haas, I958). MFD also occurs even in liquid medium enriched with a mixture of amino acids if protein synthesis inhibitors, such as chloramphenicol, are present (Doudney \& Haas, 1959). Witkin (196I, 1963, I966, I969) has subsequently interpreted MFD in terms of caffeine-sensitive localized excision repair acting, under conditions of arrested protein synthesis, to remove potentially mutagenic lesions from tRNA, nonsense suppressor, loci. According to Witkin (I966), there is no common influence of the broth effect or MFD upon the yield of other types of mutations, e.g. to streptomycin-resistance (Witkin \& Theil, 1960) or true back-mutations (Bridges, Dennis \& Munson, 1967), nor upon lethality.

* Present address: Department of Biology, University of California at San Diego, La Jolla, California 9203 I, U.S.A. 
Initially Witkin (1956) used mainly a Trp- strain of Salmonella typhimurium in her experiments on the nature of the broth effect. Stationary phase cells grown in nutrient broth or tryptophan-supplemented minimal medium were used in these early studies. Subsequently Escherichia coli $\mathrm{B} / \mathrm{r}$ auxotrophs have been used. Furthermore, in her later studies, Witkin has used only late lag phase broth-grown cells on the grounds (Witkin, 1966) that MFD is much more pronounced for these late lag phase broth-grown cells than for broth-grown exponential or stationary phase cells. Other authors have, however, used exponential phase cells grown in minimal medium plus the specific auxotrophic requirement in their experiments on MFD (Doudney \& Young, 1962; Bridges, et al. 1967). In our present experiments we have used the Trp- $S$. typhimurium strain employed by Witkin (I956) in her initial experiments and have measured the caffeine and broth effects on plates and MFD in liquid minimal medium for lag, exponential and stationary phase cells grown in broth or tryptophan-supplemented minimal medium. This has enabled us to compare results obtained with $E$. coli $\mathrm{B} / \mathrm{r}$ and $S$. typhimurium. Furthermore, we have tested the influence of the dark-repair inhibitor caffeine and an amino acid mixture (acid hydrolysed casein), separately and together, not only upon mutational yield but also on survival levels for cells of all six growth conditions.

The results as a whole allow us to test the contention that there is no direct correlation between the broth effect, or MFD, and survival changes and that MFD identical to that observed in liquid medium is the sole and complete explanation for the broth effect found on plates. We have noted also two unexpected phenomena. First, a true, but conditional, antimutagenic effect of caffeine and secondly a correlation between MFD kinetics and a casein hydrolysate enhancement of survival.

\section{METHODS}

Strains. Salmonella typhimurium LT-2 tryptophan auxotroph $\operatorname{trp} C_{3}$ was kindly provided by Professor R. C. Clowes. This strain is deficient in tryptophan synthetase A protein activity. The tryptophan deletion mutant SL 4623, of genotype $\operatorname{trpC}$ rog deletion/ $/ \mathrm{F}^{\prime}{ }_{13} l a c^{\prime s}$, and the transducing phage P 22 variant $\mathrm{L} 4$ were supplied by Dr D. G. Macphee. SL 4623 has a short deletion in the proximal portion of the tryptophan synthetase A component gene, $\operatorname{trp} C$ (P. E. Hartman, personal communication). The $\mathrm{F}^{\prime}$ factor, which is incidental in the experiments for which the strain was used here, is lost at $45^{\circ}$.

Media, cultures, irradiation, assays of viable counts and reversions. These were as described by Clarke (1967, 1969) and Hill (1968). Colony counts were performed after three days incubation at $37^{\circ}$. Incubation up to 7 days did not give appreciably higher numbers of colonies.

$M F D$ experiments. Immediately after u.v. irradiation cells, resuspended in liquid minimal medium (devoid of tryptophan and casein hydrolysate), were incubated in a $37^{\circ}$ water-bath. At time zero and at intervals during $\mathrm{I} h$., samples were removed to assay $\operatorname{Trp}^{+}$reversions and viable counts on plates of minimal-low tryptophan-casein hydrolysate medium.

Genetic analysis of $\operatorname{Tr}^{+}$revertants. Transducing phage $\mathrm{P}_{22} \mathrm{~L}_{4}$ was grown on $\mathrm{Trp}^{+}$ revertants obtained from $\operatorname{trp} C_{3}$ itself and the histidine auxotroph hisC 869. Titres were between 6 and $8 \times 10^{9}$ p.f.u. $/ \mathrm{ml}$. The $\operatorname{trpC} \mathrm{IO} 9$ recipient was grown overnight in broth at $37^{\circ}$ and $0.5 \mathrm{ml}$. samples of lysates were mixed with $\mathrm{I} \mathrm{ml}$. portions of the recipient culture plus $0.5 \mathrm{ml}$. of fresh broth, i.e. multiplicity approximately $\mathbf{I} 0$. These mixtures were incubated at $37^{\circ}$ for $20 \mathrm{~min}$. and $0.1 \mathrm{ml}$. was spread in duplicate on minimal plates. Trp ${ }^{+}$transductant colonies were scored after 3 days incubation at $37^{\circ}$. Controls were included of lysate samples and $\operatorname{trpC}$ IOg plated alone. 
General. All the results presented here are the means of three independent experiments, and control frequencies of $\operatorname{Trp}^{+}$reversions have been subtracted in all cases.

\section{RESULTS}

Influences of caffeine and casein hydrolysate upon the survival of u.v-irradiated cells. The presence of casein hydrolysate in the post-irradiation plating medium enhanced survival only for lag and exponential phase broth-grown cells and exponential phase minimal-grown cells. There was no measurable effect of casein hydrolysate in the plating medium upon the survival of cells from the other three growth conditions (Table r). This agrees with Witkin

\section{Table I. Influences of pre-irradiation growth condition upon} post-irradiation survival and $M F D$

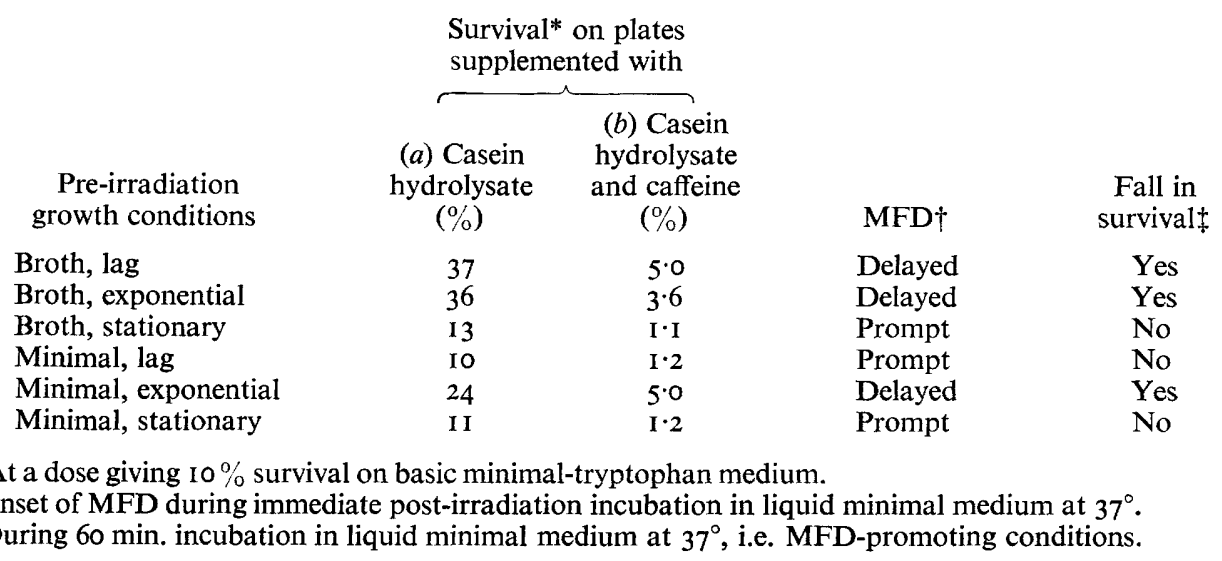

(1956) who with the same strain found no broth effect on the survival of stationary phase broth-grown cells. The addition of caffeine to the plating medium significantly decreased survival and abolished any casein hydrolysate effect upon survival. This is exactly what one would expect from the well-known action of caffeine as a dark-repair inhibitor (Witkin, 1958; Clarke 1967) provided that casein hydrolysate enhancement of survival is the result of stimulated dark-repair activity.

Influences of caffeine and casein hydrolysate upon u.v.-induced Trp ${ }^{+}$revertant yield. Induced $\mathrm{Trp}^{+}$revertants were scored in cultures prepared in all six growth conditions when plating media supplemented with casein hydrolysate were used. In contrast, only minimal-grown lag and exponential phase cells yielded induced $\mathrm{Trp}^{+}$revertants on media devoid of casein hydrolysate, although spontaneous revertants appeared normally (Fig. I). Witkin (1956) has reported that presumed stationary phase minimal-grown cells of this same strain give appreciable numbers of u.v.-induced Trp ${ }^{+}$revertants on unenriched plates. This difference in results may be due to minor strain or cultural variations. The addition of caffeine to plating media supplemented with casein hydrolysate led, in all cases, to an increase in Trp ${ }^{+}$ revertant frequencies (Witkin, I958; Clarke, 1967). In the two conditions where induced Trp ${ }^{+}$ revertants arose on a plating medium devoid of casein hydrolysate, caffeine had a clearly anti-mutagenic action (Fig. 2). This was not attributable to growth delay or suppressorinhibition artefacts.

MFD experiments in liquid minimal medium. MFD experiments with u.v.-irradiated cells 
in all six growth conditions gave the following results. The onset of MFD was prompt only for stationary phase broth-grown cells and lag or stationary phase minimal-grown cells. For cells from the other three growth conditions there was an approximate $15 \mathrm{~min}$. delay before the onset of MFD (Fig. $3 b$ ). Such a delay in the onset of MFD has not been reported for Escherichia coli $\mathrm{B} / \mathrm{r}$ except in the special cases of 5-hydroxy-uridine inhibition (Doudney \& Haas, 1959) and the MFD- mutant 36-10-45 (Clarke, 1969). Where the onset of MFD was

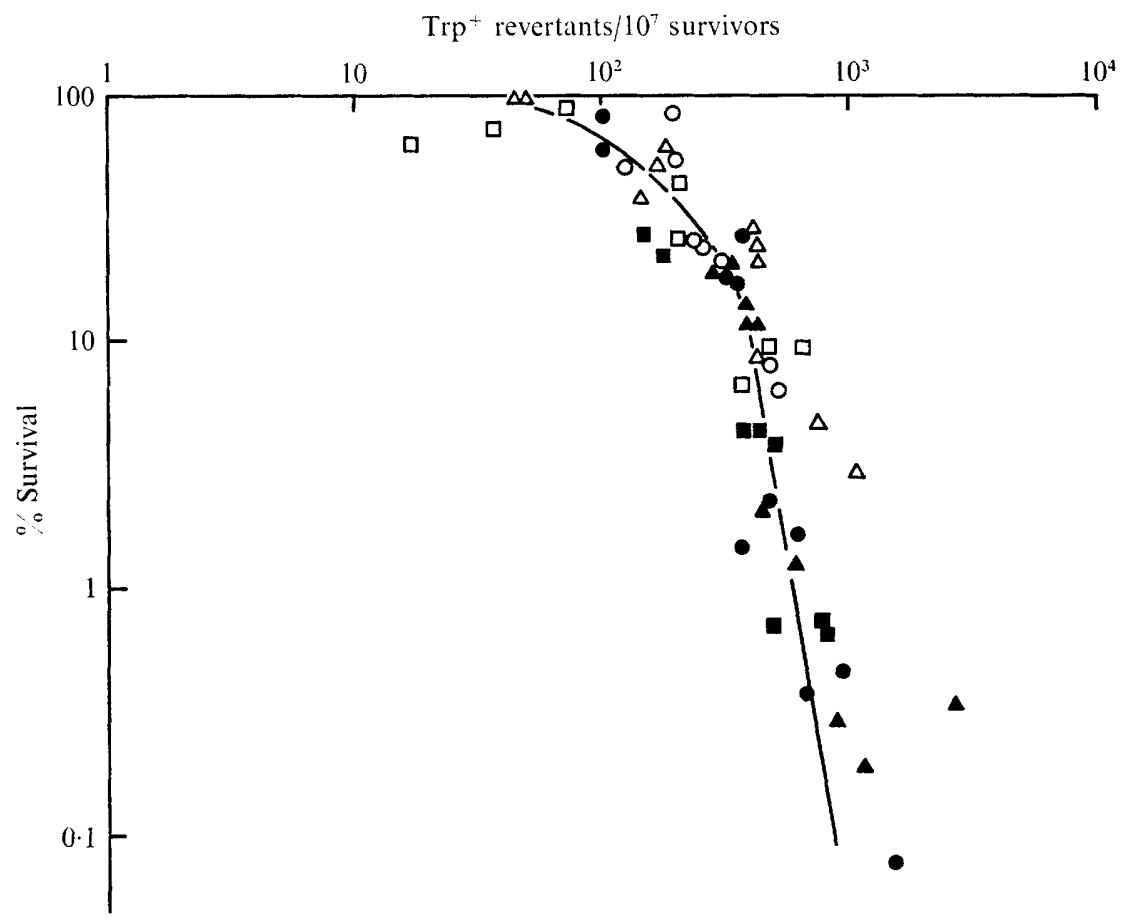

Fig. I. The influences of casein hydrolysate and caffeine supplementation of the basic minimal medium, containing I $\mu$ g. L-tryptophan $/ \mathrm{ml}$. upon u.v.-induced Trp ${ }^{+}$reversion frequencies. Brothgrown cells of the three growth phases have been used and Trp ${ }^{+}$reversion frequencies are plotted against percentage survivals. $O$, Lag phase cells on medium with casein hydrolysate;, lag phase cells on medium with casein hydrolysate and caffeine; $\triangle$, exponential phase cells on medium with casein hydrolysate; $\boldsymbol{\Delta}$, exponential phase cells on medium with casein hydrolysate and caffeine; $\square$, stationary phase cells on medium with casein hydrolysate; $\mathbf{a}$, stationary phase cells on medium with casein hydrolysate and caffeine.

delayed, there was also a delayed fall in survival to 30 to $50 \%$ of the initial level, during the $60 \mathrm{~min}$. period of incubation in liquid minimal medium (Fig. $3 a$ ). Where the onset of MFD was prompt, no such fall in survival was observed during the entire $60 \mathrm{~min}$. incubation period. The maximum extent of decrease in $\operatorname{Trp}^{+}$revertant frequencies observed in all these MFD experiments was five- to tenfold.

Genetic analysis of $\mathrm{Tr}^{+}$revertants. Transducing phage was propagated on $25 \mathrm{Trp}^{+}$ revertants which were isolated on low tryptophan-casein hydrolysate medium following u.v. irradiation of broth-grown lag phase cells. The lysates were tested as described in Methods against the tryptophan deletion recipient strain on minimal medium. The appearance of Trp ${ }^{+}$transductants was taken to be indicative of the presence in any particular revertant of a back-mutation in the $\operatorname{trp} C$ locus, or of a very closely-linked suppressor 
within the region covered by the deletion. As a result of this test 24 of the 25 tested revertants were clearly due to unlinked suppressors. Of the 25 revertants tested approximately two were calculated to have been of spontaneous origin and the remainder to have been actually induced by the u.v. irradiation.

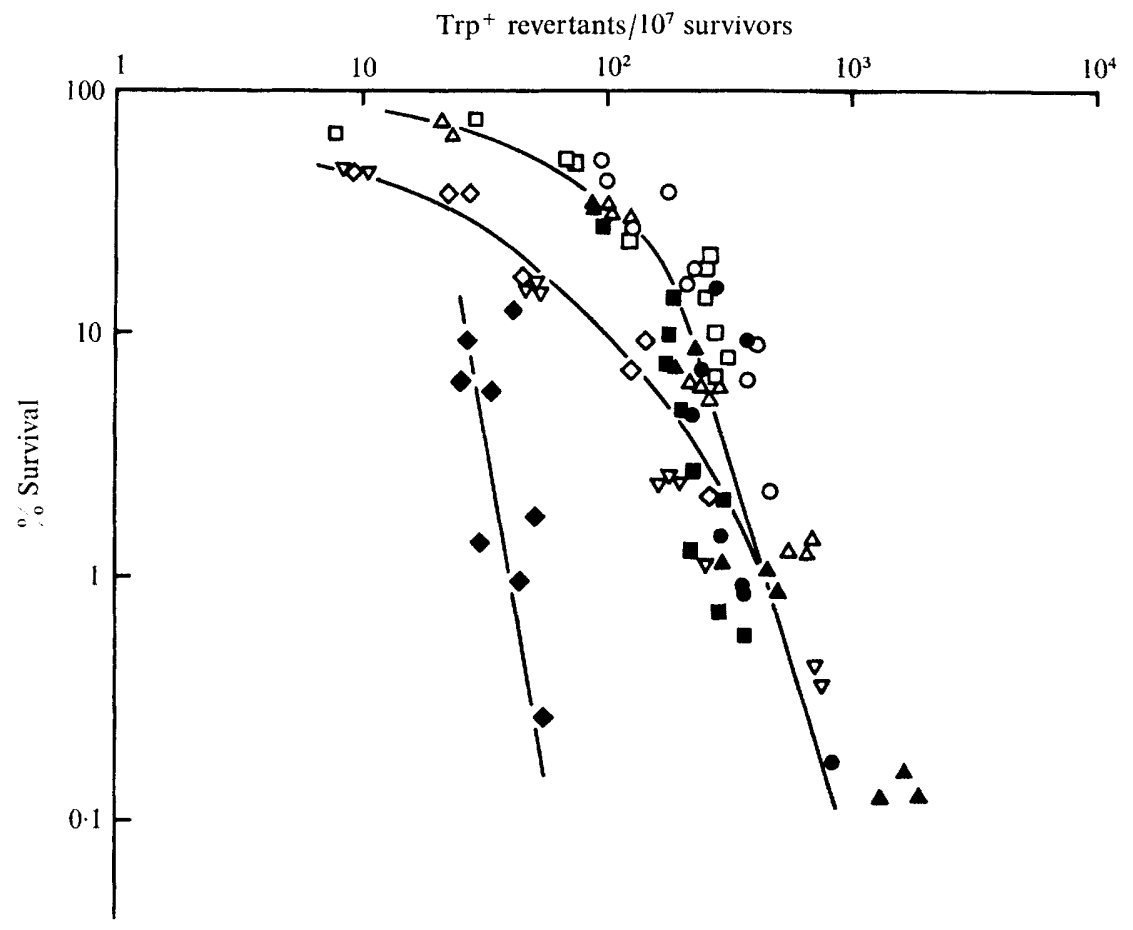

Fig. 2. The influence of casein hydrolysate and caffeine supplementation of the plating medium upon u.v.-induced $\mathrm{Trp}^{+}$reversion frequencies. Cells of all three growth phases were grown in minimal medium plus $20 \mu \mathrm{g}$. L-tryptophan $/ \mathrm{ml}$. Basic plating medium is minimal plus I $\mu \mathrm{g}$. Itryptophan $/ \mathrm{ml}$. and $\operatorname{Trp}^{+}$reversion frequencies are plotted against percentage survivals. $\diamond, \mathbf{L a g}$ phase cells on basic plating medium; $\diamond$, lag phase cells on basic plating medium + caffeine; $O$, lag phase cells on basic plating medium + casein hydrolysate; $\bullet$, lag phase cells on basic plating medium + casein hydrolysate +caffeine; $\nabla$, exponential phase cells on basic plating medium; $\triangle$, exponential phase cells on basic plating medium + casein hydrolysate; $\boldsymbol{\Lambda}$, exponential phase cells on basic plating medium + casein hydrolysate + caffeine; $\square$, stationary phase cells on basic plating medium + casein hydrolysate; $\mathbf{E}$, stationary phase cells on basic plating medium + casein hydrolysate + caffeine.

\section{DISCUSSION}

Our main findings are, first, that the extent of the broth effect upon u.v.-induced Trp ${ }^{+}$ revertants is very dependent upon the pre-irradiation growth conditions of the cells. In the only two cases (lag and exponential phase minimal-grown cells) in which any induced Trp ${ }^{+}$ revertants arose in the absence of casein hydrolysate from the plating medium, caffeine had a decided anti-mutagenic action. This was not explicable in terms of lowered survival nor by inhibition of the growth of established $\mathrm{Trp}^{+}$revertants into visible colonies, but may have resulted from decreased error-proneness and/or decreased activity of a post-replication recombinational repair system (Witkin, 1969).

Secondly, in all cases in which we have carried out classical MFD experiments in liquid 
minimal medium, there was no obvious correlation between the occurrence or kinetics of survival changes and those of Trp ${ }^{+}$revertant frequency decrease. The falls in survival we observed in some MFD experiments did not occur at the same time as MFD but later, and could have resulted from prophage induction since the LT-2 strain of Salmonella typhimurium is known to be lysogenic. There was a good correlation between the occurrence of an enhanc-
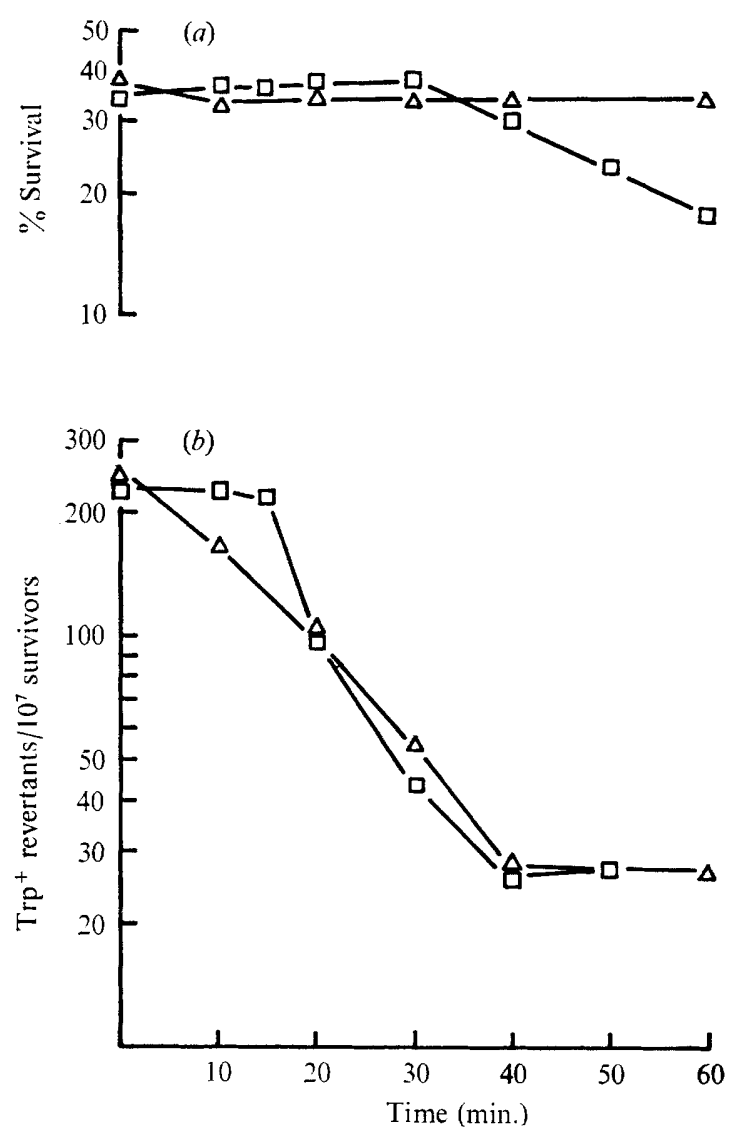

Fig. 3. Prompt and delayed modes of mutation frequency decline in Salmonella typhimurium. Percentage survival (Fig. $3 a$ ) and Trp ${ }^{+}$reversion frequencies (Fig. $3 b$ ) are plotted against period of post-irradiation incubation in liquid minimal medium. Ultraviolet dose $=266 \mathrm{ergs} . / \mathrm{mm}^{2} . \square$, Exponential phase broth-grown cells; $\Delta$, stationary phase broth-grown cells.

ing effect of casein hydrolysate (added to the plating medium) upon survival and the occurrence, during MFD experiments, of a decline in survival. Cells showing these two phenomena were also those in which the onset of MFD was delayed. These correlations may be explained, perhaps, on the basis of the sizes of the intracellular free amino acid pools. Thus bacteria with low amino acid pools might demonstrate a delay in synthesizing, or developing an accessibility of lesions to, the repair enzymes responsible for MFD, a marked effect upon survival of extraneously supplied amino acids, and a failure to maintain adequate levels of phage repressor in the cell so resulting in prophage induction.

One of us (P. H. W.) is supported by a grant from the Science Research Council. We acknowledge also funds and equipment supplied by the Medical Research Council and the 
University of East Anglia. Our special thanks go to Professor Ruth F. Hill for recent discussions and suggestions and to Mrs Pat Howes for excellent technical assistance.

\section{REFERENCES}

BRidges, B. A., Dennis, R. E. \& Munson, R. J. (I967). Differential induction and repair of ultraviolet damage leading to true reversions and external suppressor mutations of an ochre codon in Escherichia coli $\mathrm{B} / \mathrm{r}$ WP 2. Genetics 57, 897-908.

Clarke, C. H. (1967). Caffeine- and amino acid-effects upon try ${ }^{+}$revertant yield in u.v.-irradiated $\mathrm{hcr}^{+}$and hcr- mutants of Escherichia coli $\mathrm{B} / \mathrm{r}$. Molecular and General Genetics 99, 97-108.

CLARKE, C. H. (I969a). Influence of cellular physiology on the realization of mutations - results and prospects. Ciba Foundation Symposium on Mutation as Cellular Process, pp. 17-28. Edited by G. E. W. Wolstenholme \& M. O'Connor. London: Churchill.

Clarke, C. H. (1969b). Chemical mutagenesis in Escherichia coli $\mathrm{B} / \mathrm{r}$; the influence of repair systems for u.v. damage. Mutation Research 8, 35-4I.

Demerec, M. \& CAHN, E. (1953). Studies of mutability in nutritionally deficient strains of Escherichia coli. Journal of Bacteriology 65, 27-36.

DOUDNEY, C. O. \& HAAS, F. L. (1958). Modification of ultraviolet-induced mutation frequency and survival in bacteria by post-irradiation treatment. Proceedings of the National Academy of Sciences 44, 390-40I.

Doudney, C. O. \& HAAS, F. L. (1959). Mutation induction and macromolecular synthesis in bacteria. Proceedings of the National Academy of Sciences 45, 709-722.

DoudNey, C. O. \& YounG, C. S. (1962). Ultraviolet light induced mutation and deoxyribonucleic acid replication in bacteria. Genetics 47, I $125-1138$.

HILL, R. F. (1965). Ultraviolet-induced lethality and reversion to prototrophy in Escherichia coli strains with normal and reduced dark repair ability. Photochemistry and Photobiology 4, 563-568.

HILL, R. F. (I968). Modification of lethality and mutagenesis by growth inhibition of ultraviolet-irradiated Escherichia coli strain B/r. Journal of General Microbiology 52, 26I-270.

WITKIN, E. M. (1956). Time, temperature, and protein synthesis: a study of ultraviolet-induced mutation in bacteria. Cold Spring Harbor Symposia on Quantiative Biology 21, I23-140.

WiTKIN, E. M. (I96I). Modification of mutagenesis initiated by ultraviolet light through post treatment of bacteria with basic dyes. Journal of Cellular and Comparative Physiology 58, Suppl. I35-I 44.

WitKIn, E. M. (1963). 'Dark repair' of mutations induced in Escherichia coli by ultraviolet light. Repair from Genetic Radiation Damage, pp. I5I-16r. Edited by F. H. Sobels. Oxford: Pergamon Press.

WrTKIN, E. M. (I966a). Mutation and the repair of radiation damage in bacteria. Radiation Research Supplement 6, 30-53.

WIrkIN, E. M. (1966b). Radiation-induced mutations and their repair. Science, New York 152, I345-I 353.

WITKIN, E. M. (1969). Ultraviolet-induced mutation and DNA repair. Annual Review of Genetics 3, 525-552.

WITKIN, E. M. \& THEIL, E. C. (I960). The effect of post-treatment with chloramphenicol on various ultravioletinduced mutations in Escherichia coli. Proceeding of the National Academy of Sciences 46, 226-231. 